\title{
PERANCANGAN DAN IMPLEMENTASI SISTEM INFORMASI SURVEY FAKULTAS DENGAN METODE MODEL VIEW CONTROLLER (MVC) DI UNIVERSITAS DHYANA PURA
}

\author{
Megawati $^{1)}{\text { Gerson } \text { Feoh }^{2)} \text { I Wayan Supriana }}^{3)}$ \\ Program Studi Teknik Informatika ${ }^{1)}$ 2) 3) \\ Fakultas Ilmu Kesehatan, Sains, dan Teknologi, Universitas Dhyana Pura, Bali. \\ megawati43@gmail.com ${ }^{1)}$ gerson.feoh@undhirabali.ac.id ${ }^{2}$ supriana@undhirabali.ac.id
}

\begin{abstract}
In this era of globalization is going very fast. Information systems have become a necessity in all aspects of life. Not only that, today information technology has even become the backbone of human life in the provision and provision of information. Through the internet is very helpful to provide ideas for writers to create a campus website that can provide information for the visitors.

At Dhyana Pura University as part of the community in Bali which organizes educational activities as a form of care and service to others in order to liberate people from ignorance, backwardness, alienation, and poverty. The information presented at Dhyana Pura University is a lot of one of the Faculty's information. In the design built there will be an addition to the student satisfaction survey. At Dhyana University Pura has two Faculties namely, Faculty of Economics \& Humanities and Faculty of Health Sciences, Science, and Technology. For prospective students can choose which faculty will be taken.
\end{abstract}

Keywords - Dhyana Pura University, Information System, PHP And MySQL, Website, Model View Controller.

ABSTRAK

Di era globalisasi saat ini berlangsung sangat cepat. Sistem informasi sudah menjadi sebuah keharusan dalam segala aspek kehidupan. Tak hanya itu, saat ini teknologi informasi bahkan telah menjadi tulang punggung kehidupan manusia dalam penyediaan dan pemberian informasi. Melalui internet tersebut sangat membantu memberikan ide bagi penulis untuk membuat suatu website kampus yang bisa memberikan informasi bagi para pengunjungnya.

Di Universitas Dhyana Pura ini sebagai bagian dari masyarakat di Bali yang menyelenggarakan kegiatan pendidikan sebagai bentuk kepedulian dan pelayanan kepada sesama dengan tujuan untuk membebaskan masyarakat dari kebodohan, keterbelakangan, keterasingan, dan kemiskinan. Informasi yang disajikan di Universitas Dhyana Pura ini banyak sekali salah satunya informasi Fakultas. Pada rancangan yang dibangun akan ada penambahan untuk survey kepuasan mahasiswa. Di Universitas Dhyana Pura memiliki dua Fakultas yaitu, Fakultas Ekonomika \& Humaniora dan Fakultas Ilmu Kesehatan, Sains, dan Teknologi. Bagi calon mahasiswa dapat memilih Fakultas mana yang akan diambil.

Kata Kunci - Universitas Dhyana Pura, Sistem Informasi, PHP Dan MySQL, Website, Model View Controller. 


\section{PENDAHULUAN}

Universitas Dhyana Pura sebagai bagian dari masyarakat di Bali berupaya untuk menyelenggarakan kegiatan pendidikan sebagai bentuk kepedulian dan pelayanan kepada sesama dengan tujuan untuk membebaskan mas-yarakat dari kebodohan, keterbelakangan, keterasingan, dan kemiskinan. Sampai sekarang kegiatan pendidikan dimulai dari tingkat dasar, menengah, dan tinggi terus dijalankan sebagai komitmen untuk ikut mencerdaskan kehidupan bangsa dan mengisi kemerdekaan melalui pembangunan bidang pendidikan. Meskipun upaya tersebut banyak mengalami hambatan dan tantangan, hasil yang dicapai tidaklah mengecewakan, terbukti dengan banyaknya kepercayaan masyarakat berpartisipasi ikut dalam proses pelaksaan kegiatan pendidikan. Universitas Dhyana Pura memiliki dua Fakultas yaitu, Fakultas Ekonomika \& Humaniora dan Fakultas Ilmu Kesehatan, Sains, dan Teknologi. Penulis memperbaharui Fakultas dengan menambahkan survey di setiap Fakultas, karena mahasiswa wajib untuk mensurvey apa yang ada di Fakultas dengan beberapa aspek-aspek yang dimilki agar mahasiswa tahu kualitas yang di miliki oleh Fakultas.

Perkembangan sistem informasi di era globalisasi saat ini berlangsung sangat cepat. Sistem informasi sudah menjadi sebuah keharusan dalam segala aspek kehidupan. Tak hanya itu, saat ini teknologi informasi bahkan telah menjadi tulang punggung kehidupan manusia dalam penyediaan dan pemberian informasi. Keberadaan sebuah informasi yang realtime, cepat, dan akurat menjadi hal yang sangat penting bagi kelangsungan hidup manusia saat ini. Data dan informasi yang diperlukan tentu harus mudah diakses dengan efektif dan efisien oleh berbagai pihak yang berkepentingan. Informasi yang diperoleh bermacam-macam tergantung dari informasi yang dibutuhkan user (pemakai). Dengan sebuah website, masyarakat dapat dengan mudah mengakses dan mengetahui segala sesuatu mengenai kampus dengan cepat tanpa memerlukan waktu yang banyak. Oleh karena itu, sistem yang dirancang menggunakan metode model view controller yang data-datanya terpisah masingmasing sesuai dengan peran metode itu sendiri, agar pada saat pengolahan data, update data dan lain-lain tidak mengalami eror yang bersamaan dan lebih mudah untuk mengetahui eror tersebut.

\section{TINJAUAN PUSTAKA}

\section{Konsep Dasar Sistem Informasi}

Suatu sistem adalah suatu jaringan kerja dari prosedur-prosedur yang saling berhubungan berkumpul bersama-sama untuk melakukan suatu kegiatan atau untuk menyelesaikan suatu sasaran tertentu. Pendekatan sistem yang lebih menekankan pada elemen atau kelompoknya mendefinisikan sistem sebagai berikut: Sistem adalah kumpulan dari elemenelemen yang berinteraksi untuk mencapai suatu tujuan tertentu. Menurut Jogiyanto (1999: 1). Suatu sistem mempunyai karakteristik atau sifat-sifat yang tertentu yaitu :

1. Komponen sistem (Components)

Suatu sistem terdiri dari sejumlah komponen yang saling berinteraksi, yang bekerja sama membentuk suatu kesatuan. Komponen-komponen sistem tersebut dapat berupa suatu bentuk subsistem. Suatu sistem dapat mempunyai sistem yang lebih besar, yang disebut dengan supra sistem.

2. Batas sistem (Boundary)

Batas sistem merupakan daerah yang membatasi antara sistem dengan sistem lainnya atau sistem dengan lingkungan luarnya. Batasan sistem ini memungkinkan suatu sistem dipandang sebagai satu kesatuan yang tidak dapat dipisah-pisahkan.

3. Lingkungan luar (Environment)

Bentuk apapun yang ada diluar ruang atau batasan sistem yang mempengaruhi operasi sistem tersebut dengan lingkungan luar sistem. Lingkungan luar sistem dapat menguntungkan dan dapat juga merugikan.

4. Penghubung sistem (Interface)

Penghubung sistem adalah media yang menghubungkan sistem dengan sistem yang lainnya. Penghubung ini memungkin- 
kan sumber-sumber daya mengalir dari suatu subsistem ke subsitem yang lainnya. Keluaran suatu subsistem akan menjadi masukan untuk subsistem yang lain dengan melewati penghubung.

5. Masukan subsistem (Input) Masukan adalah Energi yang dimasukan ke dalam sistem. Masukan dapat berupa masukan perawatan dan masukan sinyal. Energi yang dimasukan agar sistem dapat beroperasi disebut masukan perawatan. Begitupun sebaliknya.

6. Keluaran sistem (Output)

Hasil dari energi yang diolah dan diklasifikasikan akan menjadi keluaran yang berguna. Keluaran ini merupakan masukan bagi subsistem yang lain.

7. Pengolahan sistem (Process)

Suatu sistem dapat mempunyai suatu proses yang akan merubah masukan menjadi keluaran.

8. Sasaran sistem (Objective) dan tujuan (Goal)

Suatu sistem memiliki sasaran dan tujuan yang pasti dan bersifat deterministic. Kalau sistem tidak memiliki sasaran, maka operasi sistem tidak ada gunanya. Suatu sistem dikatakan berhasil bila mengenai sasaran atau tujuan yang telah direncanakan.

\section{Metode Model View Controoler}

Model View Controller pertama kali dipublikasikan oleh peneliti XEROX PARAC yang bekerja dalam pembuatan bahasa pemrograman Smalltalk sekitar tahun 1970-1980. MVC adalah sebuah metode untuk membuat sebuah aplikasi dengan memisahkan data (Model) dari tampilan (View) dan cara bagaimana memprosesnya (Controller). Dalam implementasinya kebanyakan framework dalam aplikasi website adalah berbasis arsitektur MVC. MVC memisahkan pengembangan aplikasi berdasarkan komponen utama yang membangun sebuah aplikasi seperti manipulasi data, antarmuka pengguna, dan bagian yang menjadi kontrol dalam sebuah aplikasi web. Bagian Model View Controller :
1. Model

Model mewakili struktur data. Biasanya model berisi fungsi-fungsi yang membantu seseorang dalam pengelolaan basis data seperti memasukkan data ke basis data, pembaruan data dan lain-lain.

2. View

View adalah bagian yang mengatur tampilan ke pengguna. Bisa di katakan berupa halaman web.

3. Controller

Controller merupakan bagian yang menjembatani model dan view. Controller berisi perintah-perintah yang berfungsi untuk memproses suatu data dan mengirimkannya ke halaman web.

Arsitektur sistem jika dikembangkan dengan menggunakan pola MVC:

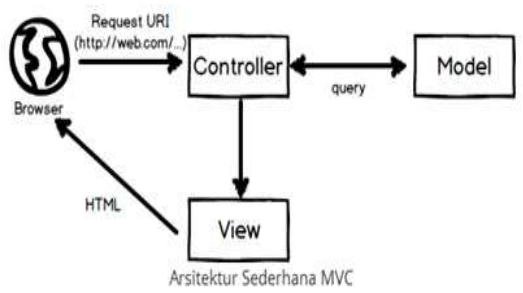

\section{Gambar 1 Arsitektur MVC}

Alur kerja sistem web ketika user mengunjungi salah satu halaman yaitu:

1. Browser berhubungan dengan server untuk akses halaman.

2. Request (permintaan) browser ditangani oleh bagian Controller dari kode.

3. Controller akan melakukan pemanggilan ke model untuk mendapatkan data yang relevan, dan kemudian mempersiapkan data tersebut untuk ditampilkan.

4. Controller memberikan data yang diperlukan kepada view.

5. View menampilkan data dan berbagai elemen antarmuka tambahan yang diperlukan. 


\section{METODE PENELITIAN}

\section{Metode Pengumpulan Data}

Untuk memperoleh data dan inform-asi dalam menyusun skripsi, maka diperlukan metode dalam pengumpulan data. Adapun metode pengumpulan data yang digunakan penulis dalam memperoleh data yaitu :

1. Observasi

Metode pengumpulan data dengan melakukan pengamatan langsung kelokasi penelitian.

2. Studi Kepustakaan

Mempelajari buku-buku yang dijadikan sebagai acuan untuk pembuatan dan penyampaian sistem informasi fakultas berbasis $P H P$ dan MySQL.

3. Wawancara

Metode pengumpulan data dengan mengajukan pertanyaan-pertanyaan kepada pihak-pihak terkait yang berhubungan dengan kegiatan penelitian.

\section{Analisis Sistem}

Pada tahap ini penulis menganalisis struktur dan alur sistem pada sistem yang sedang berjalan pada Fakultas di Universitas Dhyana Pura, apakah struktur dan alur sistem telah efisien dan sesuai dengan standar tertentu. Dalam tahap analisis ini akan diuraikan mengenai :

1. Sistem informasi yang sedang berjalan, serta diuraikan mengenai tahapan proses dari sistem informasi yang sedang berjalan.

2. Identifikasi masalah dari struktur dan alur sistem yang sedang berjalan.

\section{Analisis Kebutuhan Fungsional}

Analisis kebutuhan fungsional menggambarkan proses kegiatan yang akan diterapkan dalam sebuah sistem dan menjelaskan kebutuhan yang diperlukan sistem agar dapat berjalan dengan baik.

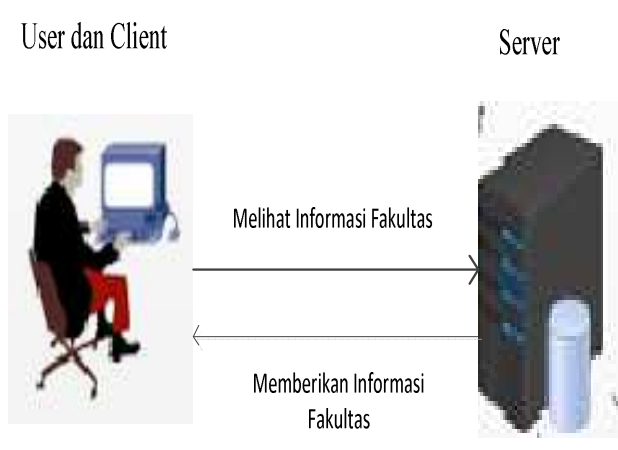

Gambar 2 Arsitektur sistem yang dibangun

Gambar 2 menjelaskan tentang arsitek-tur sistem yang akan dibangun. user sebagai pengguna dan client merujuk sebagai perangkat yang digunakan pengguna, kemudian user akan melihat informasi fakultas ke server dan kemudian server akan memberikan informasi fakultas ke client agar user dapat melihat informasi yang diinginkan.

\section{Analisis Kebutuhan Non Fungsional}

Kebutuhan non fungsional menjelaskan seperti apa spesifikasi dari sistem yang dibangun dari sisi performa, kontrol, informasi, efisien, dan pelayanan.

1. Performa.

Hal ini bisa dilihat dari proses pengolahan data informasi mahasiswa yang dibutuhkan oleh setiap user yang akan mencari informasi di website fakultas, agar mempermudah setiap pencarian informasi tentang fakultas untuk user.

2. Kontrol

Pengendalian atau kontrol dalam sebuah sistem sangat diperlukan untuk menghindari dan mendeteksi secara dini terhadap penyalahgunaan atau kesalahan sistem serta untuk menjamin keamanan data dan informasi.

3. Informasi

Informasi merupakan komuditas krusial bagi pengguna. Evaluasi terhadap sistem dalam menghasilkan informasi yang ber- 
manfaat perlu dilakukan untuk menyikapi peluang dan menangani masalah yang muncul.

4. Efisien

Target penggunaan waktu yang belum minimal mengakibatkan admin kewalahan dalam pengolahan data informassi fakultas tersebut, sering terjadinya kesalahan dan dilakukan pengulangan pekerjaan atau cek ulang data informasi untuk menghindari kesalahan agar tidak terjadi kesalahan kembali.

5. Pelayanan

Peningkatan pelayanan yang lebih baik di Universitas Dhyana Pura Bali untuk memberikan pelayanan yang terbaik.

\section{Perancangan Sistem}

Proses perancangan mengubah kebutuhan-kebutuhan menjadi bentuk karakteristik yang dimengerti perangkat lunak sebelum dimulai penulisan program. Perancangan ini harus didokumentasikan dengan baik dan menjadi bagian konfigurasi perangkat lunak.

\section{Arsitektur Sistem yang dibangun Dengan Metode Model View Controller (MVC)}

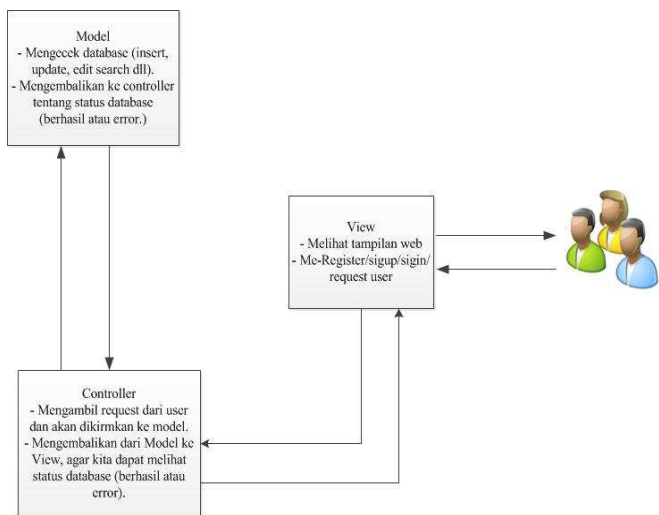

Gambar 3 Arsitektur Sistem yang dibangun

Gambar 3 menjelaskan bahwa sistem yang akan dibangun akan menggunakan metode Model View Controller (MVC). Pada model dimaksudkan bahwa ketiga peran pada metode tersebut, View akan menerima request dari user kemudian Controller akan mengambil request user dari View dan dikirimkan ke model. Controller akan mengirimkan data user ke Model agar cek database seperti insert, update, edit dan search dan lain-lain dan kemudian dikembalikan ke Controller apakah status database tersebut berhasil atau eror.

\section{Model Sistem}

Perancangan yang akan dilakukan pada model sistem yang diusulkan meliputi rancangan basis data atau database yang terdiri dari :

1. Flowchart.

2. Diagram Konteks.

3. Data Flow Daigram (DFD).

4. Entity Relationship Diagram (ERD).

5. Perancangan Database.

\section{Flowchart Login Super Admin dan User.}

a. Flowchart Login Super Admin

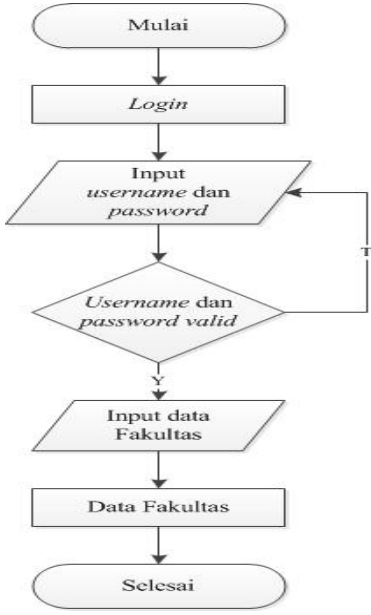

\section{Gambar 4 Flowchart Login Super Admin}

Pada gambar 4 flowchart login super admin yang dibangun akan dijelaskan, mulai lalu login. Kemudian memulai proses memasukkan username dan password, jika username dan password kondisi salah maka kembali ke proses input username dan password dan jika benar maka proses akan input data fakultas dan menghasilkan data fakultas, selesai. 


\section{b. Flochart Untuk Mengisi Survey.}

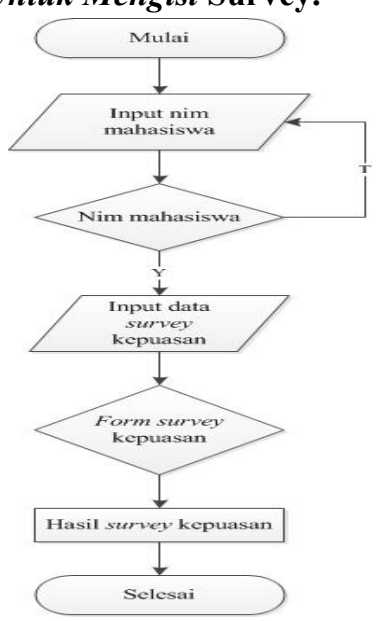

\section{Gambar 5 Flowchart Untuk Mengisi Survey}

Pada gambar 5 Flowchart User untuk mengisi survey yang dibangun akan dijelaskan, mulai. Kemudian memulai proses memasuk-kan nim mahasiswa, jika nim mahasiswa kon-disi salah maka kembali ke proses input nim mahasiswa dan jika benar maka proses akan input data survey fakultas kemudian mengisi form survey kepuasan dan menghasilkan data survey kepuasan, selesai.

\section{Diagram Konteks}

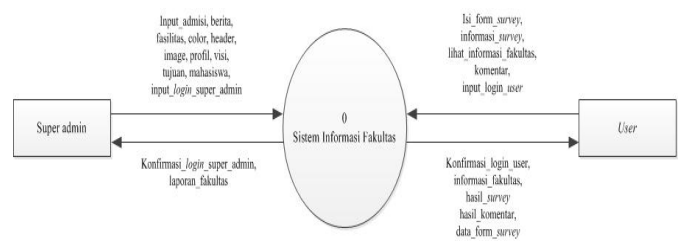

\section{Gambar 6 Diagram Konteks}

Pada gambar 6 diagram konteks menjelaskan bahwa masing-masing pada entity memiliki tugas sesuai dengan yang diinputkan. Admin akan login dengan memasukkan username dan password, jika berhasil maka valid kemudian input data admisi, berita, fasilitas, color, header, image, profil, visi, tujuan, mahasiswa dan sistem akan memberikan data fakultas. User juga login dengan username dan password, jika berhasil maka valid kemudian akan mengisi formulir survey, melihat informasi fakultas, melihat informasi survey komentar, kemudian sistem akan memberikan informasi fakultas, hasil survey, hasil komentar dan data form survey.

\section{Data Flow Diagram (DFD) Level 0 Fakultas}

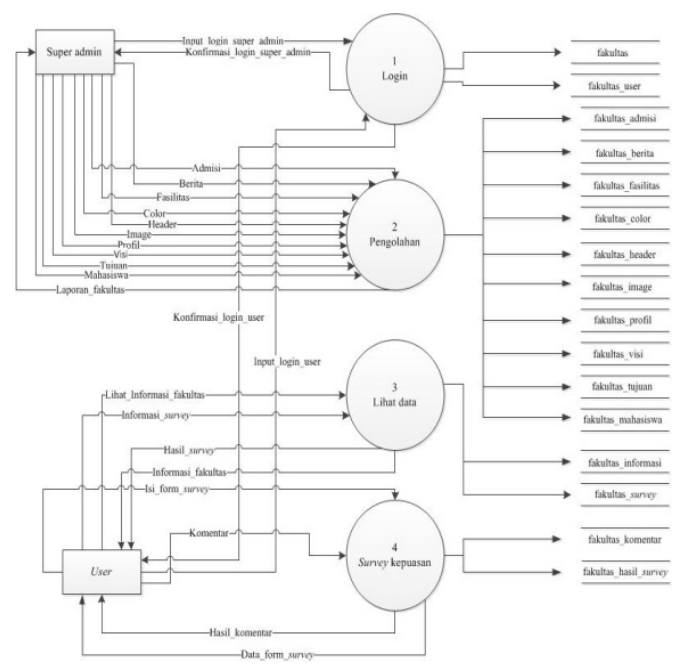

Gambar 7 DFD Level 0 Fakultas

Gambar 7 menjelaskan tentang DFD Fakultas. Super admin dan user akan login dengan memasukkan username dan password dan disimpan ke database fakultas, database fakultas user. Super admin akan mengelola data admisi, berita, color, fasilitas, header, image, mahasiswa, profil, tujuan, visi dan disimpan pada masing-masing database tersebut dan sistem memberikan laporan data fakultas. User melihat informasi fakultas dan melihat hasil survey yang telah dilakukan dan sistem memberikan informasi fakultas dan hasil survey ke user dan disimpan di database fa-kultas informasi dan database fakultas survey. User melakukan survey kepuasan dengan isi form survey kepuasan kemudian sistem mem-berikan data form survey dan user juga bisa mengisi komentar setelah mengisi data form survey, sistem memberikan hasil survey yang diisi oleh mahasiswa dan disimpan ke data-base fakultas komentar dan database fa-kultas hasil survey. 


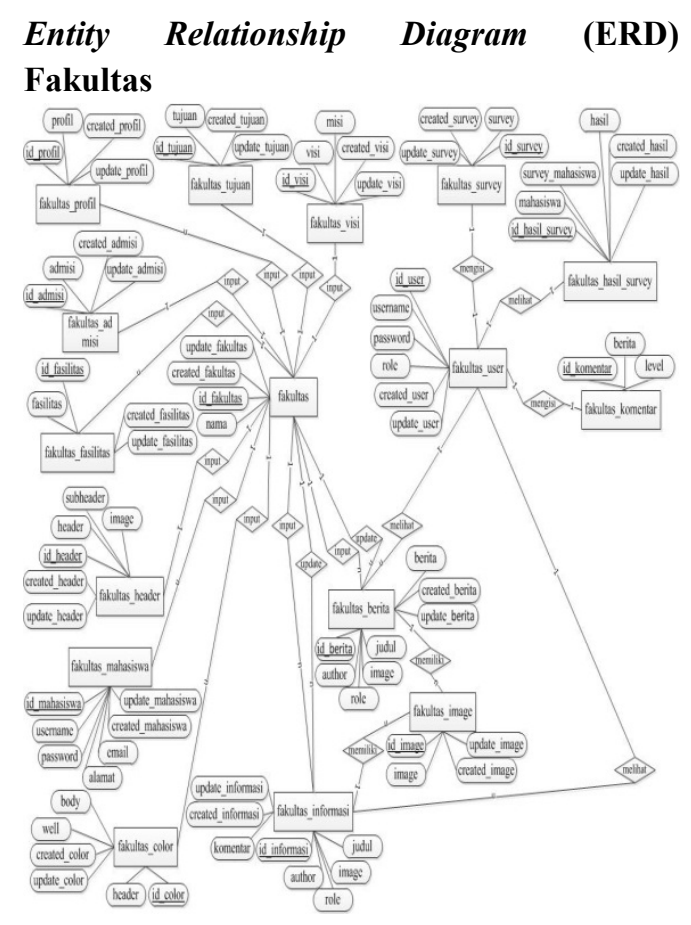

Gambar 8 ERD Fakultas

Pada gambar 8 menjelaskan, bahwa fakultas input fasilitas, informasi, mahasiswa, visi, tujuan, admisi, header, berita, color, image, Fakultas update berita dan informasi kemudian user mengisi survey kepuasan dan komentar, melihat hasil survey, melihat informasi dan melihat berita.

\section{Perancangan Database}

Adapun perancangan struktur database dilakukan dengan menggunakan MySQL. Perancangan database yang ada adalah sebagai berikut :

Tabel 1 Database fakultas

\begin{tabular}{|c|c|c|c|}
\hline No & Nama & $\begin{array}{c}\text { Tipe } \\
\text { Data }\end{array}$ & Keterangan \\
\hline 1 & id_fakultas & $\begin{array}{c}\text { varchar } \\
(225)\end{array}$ & $\begin{array}{c}\text { id untuk } \\
\text { fakultas }\end{array}$ \\
\hline 2 & nama & $\begin{array}{c}\text { varchar } \\
(225)\end{array}$ & $\begin{array}{c}\text { nama } \\
\text { fakultas }\end{array}$ \\
\hline 3 & $\begin{array}{c}\text { created_fa } \\
\text { kultas }\end{array}$ & datetime & $\begin{array}{c}\text { membuat } \\
\text { tanggal dan } \\
\text { waktu } \\
\text { fakultas }\end{array}$ \\
\hline
\end{tabular}

\begin{tabular}{|c|c|c|c|}
\hline 4 & $\begin{array}{l}\text { update_- } \\
\text { fakultas }\end{array}$ & datetime & $\begin{array}{c}\text { Memperba } \\
\text { harui } \\
\text { tanggal dan } \\
\text { waktu } \\
\text { fakultas }\end{array}$ \\
& & & \\
\end{tabular}

Pada tabel 1 database fakultas untuk menyimpan data Fakultas di Universitas Dhyana Pura, dan yang menginputkan data pada Fakultas adalah admin super.

Tabel 2 Database fakultas_mahasiswa

\begin{tabular}{|c|c|c|c|}
\hline No & Nama & $\begin{array}{c}\text { Tipe } \\
\text { Data }\end{array}$ & Keterangan \\
\hline 1 & $\begin{array}{c}\text { id_mahasis } \\
\text { wa }\end{array}$ & $\begin{array}{c}\text { varchar } \\
(225)\end{array}$ & $\begin{array}{c}\text { id } \\
\text { mahasiswa }\end{array}$ \\
\hline 2 & username & $\begin{array}{c}\text { varchar } \\
(225)\end{array}$ & $\begin{array}{c}\text { username } \\
\text { untuk } \\
\text { mahasiswa }\end{array}$ \\
\hline 3 & password & $\begin{array}{c}\text { varchar } \\
(225)\end{array}$ & $\begin{array}{c}\text { password } \\
\text { mahasiswa }\end{array}$ \\
\hline 4 & alamat & text & $\begin{array}{c}\text { alamat } \\
\text { mahasiswa }\end{array}$ \\
\hline 5 & email & $\begin{array}{c}\text { varchar } \\
(225)\end{array}$ & $\begin{array}{c}\text { email } \\
\text { mahasiswa }\end{array}$ \\
\hline 6 & $\begin{array}{c}\text { created_ma } \\
\text { hasiswa }\end{array}$ & datetime & $\begin{array}{c}\text { membuat } \\
\text { tanggal dan } \\
\text { waktu } \\
\text { mahasiswa }\end{array}$ \\
\hline 7 & $\begin{array}{c}\text { update_maha } \\
\text { siswa }\end{array}$ & datetime & $\begin{array}{c}\text { memperba } \\
\text { harui } \\
\text { tanggal dan } \\
\text { waktu } \\
\text { mahasiswa }\end{array}$ \\
\hline & & & \\
\end{tabular}

Pada tabel 2 database fakultas mahasiswa ini untuk menyimpan data mahasiswa yang akan mendaftar di Fakultas yang dikelola oleh admin super.

\section{Desain Perancangan Antarmuka}

Perancangan antarmuka dibutuhkan untuk mewakili keadaan sebenarnya dari sistem yang akan dirancang. Selain itu juga memberikan kemudahan kepada para pembuat piranti lunak untuk melakukan penempatan informasi mana yang harus ditampilkan dan informasi mana yang tidak perlu ditampilkan dalam sistem ini. Berikut ini adalah bentuk 
gambar rancangan antarmuka yang nantinya akan diimplementasikan dalam bentuk program.

\section{Desain Halaman Utama}

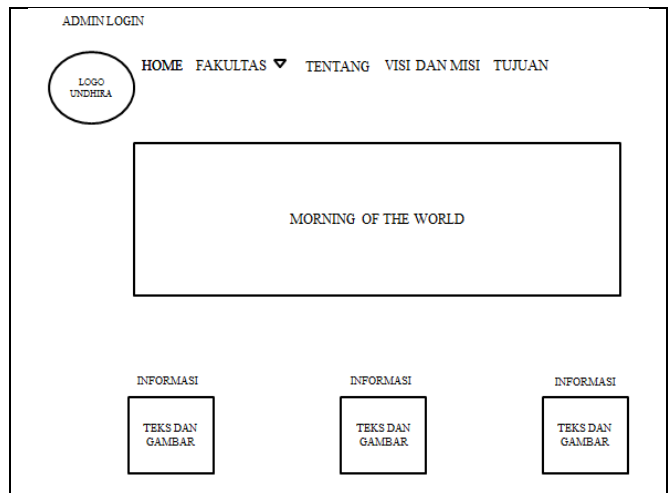

Gambar 9 Desain Halaman Utama

Pada gambar 9 menggambarkan rancangan desain interface menu utama pada halaman home, agar dapat melihat informasi di Universitas Dhyana Pura terutama informasi tentang Fakultas.

\section{HASIL DAN PEMBAHASAN}

Pada bab ini penyusun akan membahas mengenai implementasi sistem dari hasil perancangan yang telah dilakukan di Fakultas Universitas Dhyana Pura. Implementasi sistem merupakan tahapan yang dilakukan setelah perancangan sistem dilakukan.

\section{Tahap Implementasi}

Menurut penjelasan Rosa dan Shalahuddin (2013, hal. 29), "desain harus diterjemahkan ke dalam program perangkat lunak, hasil dari tahap ini adalah program komputer yang sesuai dengan desain yang telah dibuat pada tahap disain". Tahap implementasi merupakan tahap mengubah rancangan ke dalam code, atau merupakan tahap pembuatan perangkat lunak.

\section{Pengujian dan Hasil Pengujian Sistem}

Pengujian aplikasi ini menggunakan metode pengujian Black Box. Pengujian black box berfokus pada persyaratan fungsional perangkat lunak.

Tabel 3 Pengujian dan Hasil Pengujian Sistem

\begin{tabular}{|c|c|c|c|c|}
\hline No. & $\begin{array}{c}\text { Nama } \\
\text { Pengu } \\
\text { iian }\end{array}$ & $\begin{array}{c}\text { Kondisi } \\
\text { Penguji } \\
\text { an }\end{array}$ & $\begin{array}{c}\text { Hasil } \\
\text { Penguji } \\
\text { an }\end{array}$ & $\begin{array}{l}\text { Kesim } \\
\text { pulan }\end{array}$ \\
\hline 1. & $\begin{array}{c}\text { Halam } \\
\text { an } \\
\text { Utama } \\
\text { /Home }\end{array}$ & $\begin{array}{l}\text { Jika } \\
\text { user } \\
\text { pertama } \\
\text { kali } \\
\text { menjala } \\
\text { nkan } \\
\text { sistem } \\
\text { muncul } \\
\text { tampila } \\
n \text { home } \\
\text { dangan } \\
\text { menu } \\
\text { yang } \\
\text { disediak } \\
\text { an }\end{array}$ & $\begin{array}{l}\text { Muncul } \\
\text { tampilan } \\
\text { home }\end{array}$ & Valid \\
\hline 2. & $\begin{array}{c}\text { Fakul } \\
\text { tas }\end{array}$ & $\begin{array}{l}\text { Jika klik } \\
\text { tombol } \\
\text { fakultas } \\
\text { maka } \\
\text { muncul } \\
\text { pilihan } \\
\text { fakultas, } \\
\text { klik dan } \\
\text { muncul } \\
\text { halaman } \\
\text { fakultas }\end{array}$ & $\begin{array}{l}\text { Muncul } \\
\text { halaman } \\
\text { fakultas }\end{array}$ & Valid \\
\hline 3. & $\begin{array}{l}\text { Ten } \\
\text { tang }\end{array}$ & $\begin{array}{l}\text { Jika klik } \\
\text { tombol } \\
\text { tentang } \\
\text { makan } \\
\text { akan } \\
\text { muncul } \\
\text { halaman } \\
\text { tentang }\end{array}$ & $\begin{array}{l}\text { Muncul } \\
\text { halaman } \\
\text { tentang }\end{array}$ & Valid \\
\hline 4. & $\begin{array}{l}\text { Visi } \\
\text { dan } \\
\text { Misi }\end{array}$ & $\begin{array}{l}\text { Jika klik } \\
\text { tombol } \\
\text { visi dan } \\
\text { misi } \\
\text { maka }\end{array}$ & $\begin{array}{l}\text { Muncul } \\
\text { halaman } \\
\text { visi dan } \\
\text { misi }\end{array}$ & Valid \\
\hline
\end{tabular}




\begin{tabular}{|l|l|l|l|}
\hline & $\begin{array}{l}\text { akan } \\
\text { muncul } \\
\text { halaman } \\
\text { visi dan } \\
\text { misi }\end{array}$ & & \\
\hline
\end{tabular}

Tabel 3 (Lanjutan). Pengujian dan Hasil Pengujian Sistem

\begin{tabular}{|c|c|c|c|c|}
\hline No. & $\begin{array}{c}\text { Nama } \\
\text { Pengu } \\
\text { jian }\end{array}$ & $\begin{array}{c}\text { Kon } \\
\text { disi } \\
\text { Pengu } \\
\text { jian }\end{array}$ & $\begin{array}{c}\text { Hasil } \\
\text { Pengujian }\end{array}$ & $\begin{array}{l}\text { Kesim } \\
\text { pulan }\end{array}$ \\
\hline 5. & Tujuan & $\begin{array}{l}\text { Jika } \\
\text { klik } \\
\text { tombol } \\
\text { tujuan } \\
\text { maka } \\
\text { akan } \\
\text { muncul } \\
\text { hala } \\
\text { man } \\
\text { tujuan }\end{array}$ & $\begin{array}{l}\text { Muncul } \\
\text { halaman } \\
\text { tujuan }\end{array}$ & Valid \\
\hline 6. & Login & $\begin{array}{l}\text { Jika } \\
\text { klik } \\
\text { tombol } \\
\text { login } \\
\text { maka } \\
\text { muncul } \\
\text { hala } \\
\text { man } \\
\text { login } \\
\text { disertai } \\
\text { kolom } \\
\text { userna } \\
\text { me dan } \\
\text { pass } \\
\text { word }\end{array}$ & $\begin{array}{l}\text { Muncul } \\
\text { halaman } \\
\text { login }\end{array}$ & Valid \\
\hline 7. & $\begin{array}{l}\text { Fasili } \\
\text { tas }\end{array}$ & $\begin{array}{l}\text { Jika } \\
\text { klik } \\
\text { tombol } \\
\text { fasilitas } \\
\text { maka } \\
\text { muncul } \\
\text { fasilitas }\end{array}$ & $\begin{array}{l}\text { Muncul } \\
\text { halaman } \\
\text { fasilitas }\end{array}$ & Valid \\
\hline 8. & Admisi & $\begin{array}{l}\text { Jika } \\
\text { klik } \\
\text { tombol } \\
\text { admisi } \\
\text { maka } \\
\text { akan } \\
\text { muncul }\end{array}$ & $\begin{array}{l}\text { Muncul } \\
\text { halaman } \\
\text { admisi }\end{array}$ & Valid \\
\hline
\end{tabular}

\begin{tabular}{|c|c|c|c|c|}
\hline & & $\begin{array}{l}\text { hala } \\
\text { man } \\
\text { admisi }\end{array}$ & & \\
\hline 9. & Berita & $\begin{array}{l}\text { Jika } \\
\text { klik } \\
\text { tombol } \\
\text { berita } \\
\text { maka } \\
\text { kan } \\
\text { muncul } \\
\text { hala } \\
\text { man } \\
\text { berita }\end{array}$ & $\begin{array}{l}\text { Muncul } \\
\text { halaman } \\
\text { berita }\end{array}$ & Valid \\
\hline 10 & $\begin{array}{l}\text { Infor } \\
\text { masi }\end{array}$ & $\begin{array}{l}\text { Jika } \\
\text { klik } \\
\text { tombol } \\
\text { infor } \\
\text { masi } \\
\text { maka } \\
\text { akan } \\
\text { muncul } \\
\text { hala } \\
\text { man } \\
\text { infor } \\
\text { masi }\end{array}$ & $\begin{array}{l}\text { Muncul } \\
\text { halaman } \\
\text { informasi }\end{array}$ & Valid \\
\hline 11 & Survey & $\begin{array}{l}\text { Jika } \\
\text { klik } \\
\text { tombol } \\
\text { survey } \\
\text { makan } \\
\text { muncul } \\
\text { hala } \\
\text { man } \\
\text { survey } \\
\text { terdiri } \\
\text { dari } \\
\text { form } \\
\text { survey }\end{array}$ & $\begin{array}{l}\text { Muncul } \\
\text { halaman } \\
\text { survey }\end{array}$ & Valid \\
\hline 12 & $\begin{array}{l}\text { Tam } \\
\text { bah }\end{array}$ & $\begin{array}{l}\text { Ketika } \\
\text { mene } \\
\text { kan } \\
\text { tombol } \\
\text { tambah } \\
\text { pada } \\
\text { hala } \\
\text { man } \\
\text { admin } \\
\text { maka } \\
\text { akan di } \\
\text { bawa } \\
\text { ke hala } \\
\text { man } \\
\text { tambah }\end{array}$ & $\begin{array}{l}\text { Muncul } \\
\text { halaman } \\
\text { tambah }\end{array}$ & Valid \\
\hline
\end{tabular}




\begin{tabular}{|l|l|l|l|}
\hline & yang & & \\
terdiri & & \\
dari & & \\
edit, & & \\
detail, & & \\
hapus, & & \\
simpan, & & \\
batal, & & \\
dan & & \\
update & & \\
gambar & & \\
\hline
\end{tabular}

\section{Evaluasi Program}

Setelah pengguna selesai melakukan persiapan baik piranti keras maupun piranti lunak dan melakukan konfigurasi piranti lunak, langkah selanjutnya adalah melakukan proses evaluasi pada piranti lunak sistem informasi Fakultas di Universitas Dhyana Pura yang telah dibangun. Agar proses evaluasi piranti lunak menjadi lebih mudah dan terorganisir, maka proses implementasi dan uji coba dikelompokkan berdasarkan proses atau aktivitas yang dimiliki oleh piranti ini.

\section{Home Utama}
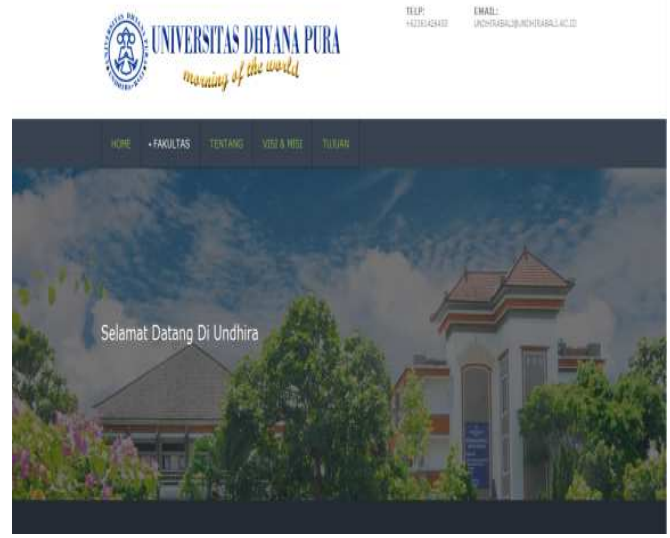

Gambar 10 Tampilan Home FEH

Pada gambar 10 tampilan untuk home fakultas Universitas Dhyana Pura. jika ingin melihat informasi lebih lanjut tentang fakultas klik saja fakultas.

\section{Tampilan Pengisian Form Survey Mahasiswa FEH}

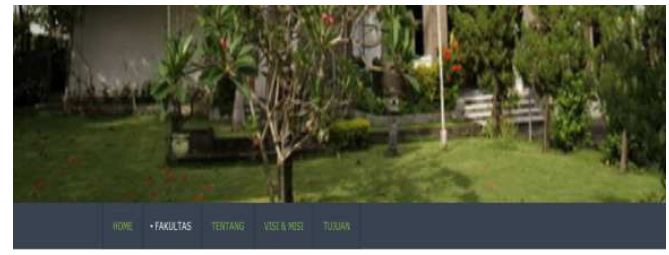

\section{Gambar 11 Tampilan Pengisian Form Survey Mahasiswa FEH}

Pada gambar 11 tampilan pengisian form survey untuk mahasiswa yang akan mengisi survey kepuasan Fakultas.

Tampilan Setelah Pengisian Form Survey Mahasiswa FEH
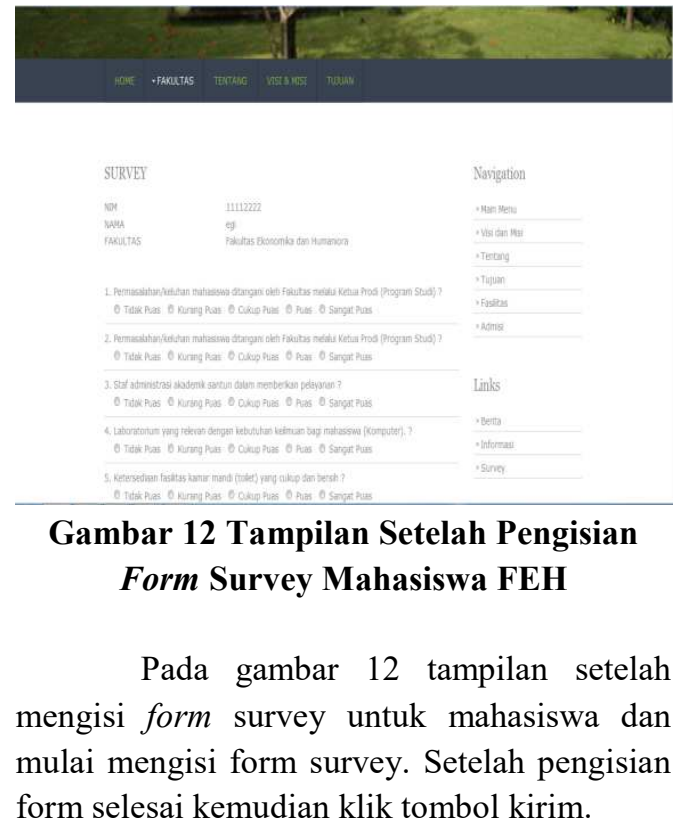


\section{Tampilan Hasil Survey FEH}
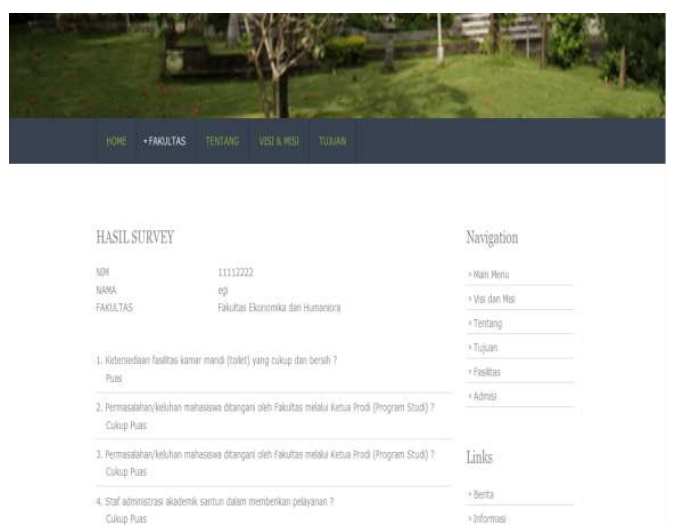

Gambar 13 Tampilan Hasil Survey

Pada Gambar 13 tampilan dari hasil survey yang diisi oleh mahasiswa Fakultas Ekonomika dan Humaniora.

\section{Tampilan Nilai Hasil Survey FEH}
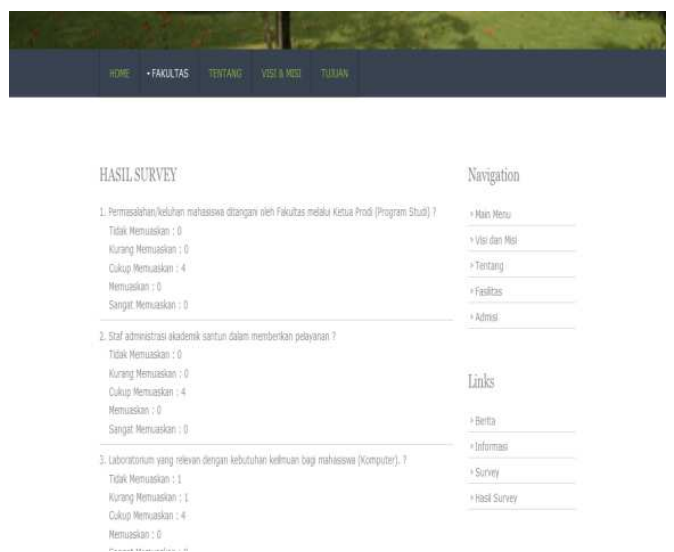

Gambar 14 Tampilan Nilai Hasil Survey

Pada gambar 14 nilai hasil dari survey yang diisi oleh mahasiswa dan bisa dilihat oleh admin dan mahasiswa.

\section{SIMPULAN}

Berdasarkan hasil dan pembahasan yang telah penulis lakukan, maka kesimpulan yang dapat diambil dari penelitian ini adalah sebagai berikut :
- Penelitian ini berhasil membangun dan merancang sistem informasi Fakultas di Universitas Dhyana Pura.

- Dari hasil penelitian ini bahwa sistem yang dirancang dan dibangun akan memberikan informasi akademik dan informasi lainnya bagi mahasiswa di Universitas Dhyana Pura.

\section{DAFTAR PUSTAKA}

[1] Ananda setyo G. 2006. Anti Kaget Internet. Creative Media, Jakarta Fatta Hanif Al. 2007. Analisis \& Perancangan Sistem Informasi. Jogjakarta : ANDI

[2] Anhar. (2010). Panduan Menguasai PHP \& MySql Secara Otodidak. Jakarta: Agromedia Pustaka.

[3] Fatta Hanif Al. 2007. Analisis \& Perancangan Sistem Informasi. Jogjakarta : ANDI Hartono, jogiyanto. MBA, Ph.D 1999. Pengennalan Komputer: Dasar ilmu komputer Pemrograman, system informasi, dan intelegensi Buatan, Yogyakarta: Andi.

[4] Kendall, K. E. \& Kendall, J.E. 202. Analisis dan Perancangan Sistem, Jilid 1. Penerbit PT. Prenhallindo, Jakarta.

[5] Jogiyanto HM. 1989. Analisis \& Disain Sistem Informasi: Pendekatan Terstruktur Teori dan Praktek Aplikasi Bisnis. Yogyakarta : Andi

[6] Madcoms 2011, Aplikasi Program PHP+MYSQL untuk Membuat Website Interaktif, Andi Offset, Yogyakarta. 